\title{
Analysis Report of Flexible System Architecture of Stand-Alone PV Power Generation with Energy Storage Device
}

\author{
Raghunandan Singh Baghel ${ }^{1}$, Ashish Bhargava ${ }^{2}$, Priyanka Mishra ${ }^{3}$ \\ M.Tech Scholar, Bhabha Engineering Research Institute Bhopal, India ${ }^{1}$ \\ Associate Prof., Bhabha Engineering Research Institute Bhopal, India ${ }^{2,3}$
}

\begin{abstract}
This paper presents a flexible design of a PV power conditioning system with energy storage. The planned conditioning unit contains a boost converter (BC), a single-phase inverter, and a bidirectional $\mathrm{dc} / \mathrm{dc}$ converter connected to the PV side of the BC. The BC regulates the dc-link bus-voltage. The bidirectional dc/dc converter endures battery bank charge/discharge control and PV maximum power point tracking (MPPT). Such design guarantees no change in controller configuration once the storage disconnects. Therefore, the previously required supervisory controller is eliminated. A system control strategy based on sliding-mode control (SMC) ensures a reliable output voltage regulation like fast dynamic response, small steady-state error, and low total harmonic distortion (THD) under step changes and nonlinear loads. A standalone photovoltaic (PV) system with energy storage needs complex control design to require into account the varied operating modes. This paper presents a flexible design of a PV power conditioning system with energy storage is executed.
\end{abstract}

Keywords: flexible stand-alone, photovoltaic (PV), PV system, Sliding-Mode Control (SMC), THD.

\section{INTRODUCTION}

A photovoltaic system, additionally solar PV power system, or PV system, may be a power system designed to provide usable solar energy by suggests that of photo voltaic. It consists of an arrangement of many elements, as well as solar panels to absorb and convert sunlight into electricity, a solar inverter to change the electrical current from DC to AC, furthermore as mounting, cabling and different electrical accessories to line up a working system. it should additionally use a solar tracking system to enhance the system's overall performance and embrace an integrated battery solution, as costs for storage devices are expected to decline. Strictly speaking, a solar battery only encompasses the ensemble of solar panels, the visible a part of the PV system, and doesn't include all the opposite hardware, usually summarized as balance of system (BOS). Moreover, PV systems convert light directly into electricity and should not be confused with different technologies, like focused solar power or solar thermal, used for heating and cooling. Environmentally friendly (renewable and clean alternatives) power generation technologies can play a very important role in future power provide because of increased global public awareness of the requirement for environmental protection and want for less dependence on fossil fuels for energy production. These technologies include power generation from renewable energy (RE) resources, like wind, photovoltaic (PV), micro hydro (MH), biomass, geothermal, ocean wave and tides, and clean alternative energy (AE) power generation technologies [such as fuel cells (FCs) and micro turbines (MTs)]. $\mathrm{RE} / \mathrm{AE}$ generation sources usually are available in the form of customized distributed generation (DG) systems in gridconnected or standalone configuration. FC and MT may even be thought-about renewable power generation sources if their input fuel is obtained from renewable sources. for example, landfill gas has been used to fuel MT, biomass will be gasified into Syngas and used as fuel for MT and FC, or hydrogen fuel will be generated using wind- or PV-generated electricity (through an electrolyzed) for FC.

Solar energy is one in all the main sources of renewable energy with the number of solar radiation reaching the earth from the Sun. it's a standard fact that the world's one year energy demand are often supplied by the Sun in one hour if it had been potential to collect all the solar energy falling on the world. There are 2 commonly used ways that of benefiting from sunlight; solar energy may be used to produce hot water or air via thermal solar panels or its potential to convert solar energy into electricity by photovoltaic (PV) cells. Photovoltaic electricity generation has numerous benefits and drawbacks. Main disadvantages are; high initial value of the equipment, low efficiency in converting solar energy into electricity and intermittent energy production because of natural reasons like no sunlight being available during the night and low solar radiation throughout the winter seasons.

Nowadays, solar energy is considered to be one amongst the most effective resources, attracting a lot of attention because of its ubiquity and sustain ability. Stand-alone photovoltaic system (SPVS) is one amongst the popular applications in photovoltaic (PV) generation and has highly practical values in off-grid areas. Such areas are classified 


\section{IARJSET

as micro grid, as well as remote areas, desert and border-outpost movable military instrumentation, street lightweight systems, etc. However, the power generation is considerably influenced by the light intensity and also the temperature. Additionally, PV cells cannot store the energy inside; therefore, an energy storage device is generally needed to balance the energy of the PV systems.

\section{THEORY}

Renewable energy sources like wind, solar, hydro and biomass can play a very important role within the future to produce increasing global energy demand and supply energy security. Analysis and development in renewable energy technologies confirm that renewable energy sources are so sustainable which green technologies will shift global dependence away from fossil fuels. making the transition to a renewable energy intensive economy would supply environmental and different advantages that can't be only measured in standard economic accounts, however in terms of reduced pollution, socioeconomic development, land restoration, abatement of world warming and fuel supply diversity [1]. From socioeconomic and environmental read points, utilization of renewable energy increases offer security, provides local solutions, lowers environmental impacts, offers property energy development and provides job opportunities. Stand-alone power systems based on renewable energy sources (RES), may provide off-grid power provide for the electrification of remote areas that aren't connected to the main grid, the powering of telecommunication stations and also the desalination of water; processes that need significant amounts of energy. Such integrated systems typically comprise a power production unit based on RES, complemented by short- and long-term energy storage units. The speed of development and application of stand-alone power systems has increased significantly over the past few years. starting from easy applications back within the 1990s with the exploitation of solar systems [1,2], the analysis society has moved to additional complicated systems with the introduction of short-term and long-term energy storage units [3-5] that aim to the efficient and cost effective operation accounting additionally for the variations in regional weather information. The analysis of such difficult and demanding systems has sparked the interest of theoretical studies that focus on the mixing of the various units through overall power management ways.

\section{METHOD}

The projected methodology describes a flexible system configuration for an SPVS with an energy device is projected. The projected stand-alone system is that the storage system is connected to the PV module directly. This configuration provides a flexible smooth operation for the system, since the role of the most PV power stream which of the storage system is clearly separated from one another. The system might work with and while not battery each, with none major mode change within the local controllers, that is preferable from industrial point of view. The projected system design makes the switch between the various modes of operation smooth and easy without the requirement for supervisory controller.

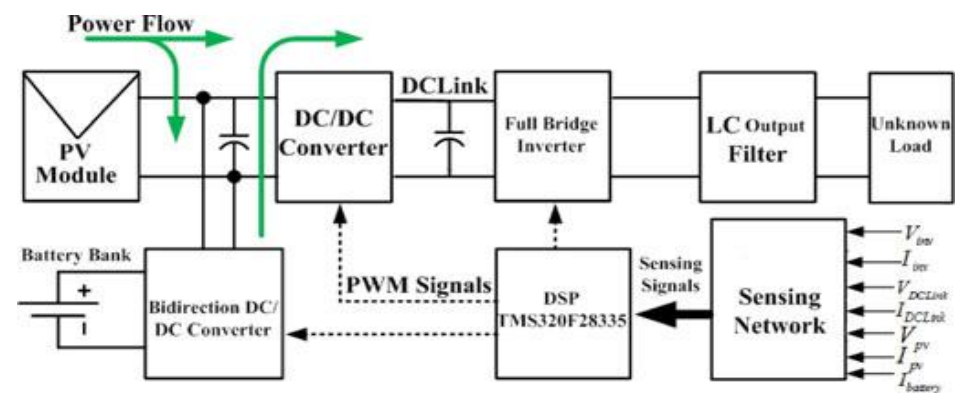

Fig. 1 Circuit Diagram of the Storage-to-PV SPVS

The projected SPVS is shown in Fig. 1 and consists of a PV panel, batteries, 2 converters, and a single-phase dc/ac inverter. The boost converter (BC) is used to maintain the dc link voltage; whereas the charging or discharging mode of the bidirectional dc/dc convertor is applied to track the MPPT of the PV array once the offered PV power is insufficient to satisfy the load. Therefore, the $2 \mathrm{dc} / \mathrm{dc}$ converters within the system ought to be coordinated by a higher level controller. This configuration provides a flexible smooth operation for the system, since the role of the most PV power stream which of the storage system is clearly separated from one another. The system might work with and while not battery each, with none major key modification within the local controllers, that is preferable from industrial point of view. The projected system design makes the switch between the different modes of operation smooth and easy while not the need for supervisory controller. moreover, this arrangement provides additional flexibility in choosing the battery's nominal voltage with a reasonable increase ratio. It additionally stores the excess PV energy within the battery to balance the system and provides the instantaneous peak power demand. One amongst the main concerns within the 
previous design is that the battery voltage, that needs stacking from multiple packs to enhance the voltage vary. Actually, the stacking up needs a balancing circuit, a so-called charge balancer, that makes the system structure additional difficult, results in an undesirable configuration in terms of the size and value competitiveness. Also, some safety issues are discovered, whereby the high-voltage dc lines will cause fatal damage to the human body since the battery is alive even during the most power system turn-off. Therefore, the projected scheme is additional desirable for the PV-storage combination system. Within the previous section, it's already been seen that the battery voltage within the conventional schemes ought to be greater than $100 \mathrm{~V}$ due to a fundamental characteristic that the bidirectional converter (BDC) ought to discharge the battery energy to $400 \mathrm{~V}$ dc link.

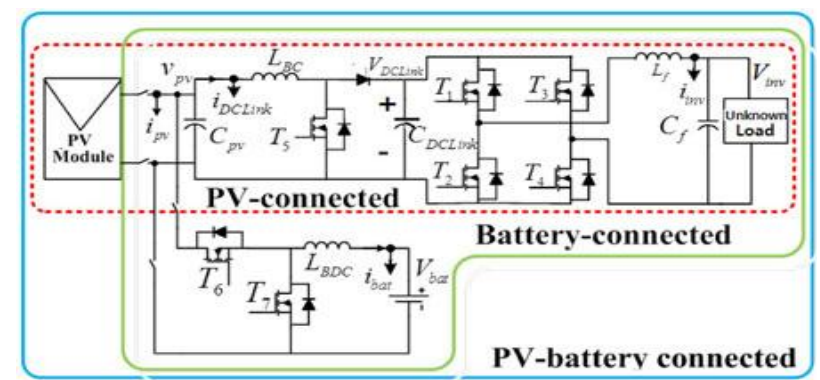

(a)

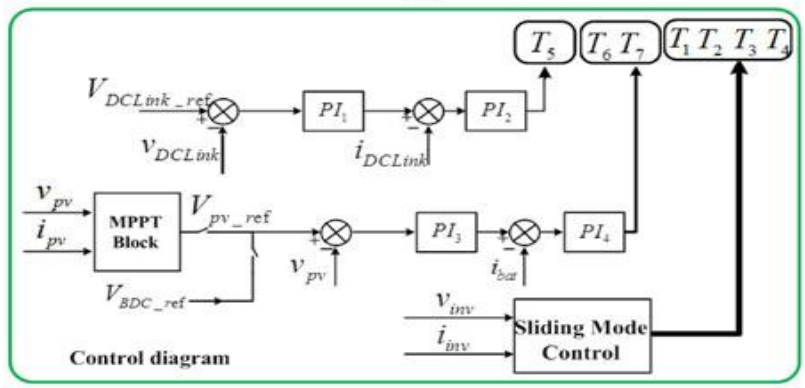

(b)

Fig.2 Block diagram of the overall system configuration of the SPVS. (a) Power stage. (b) Control strategy

\section{RESULT}

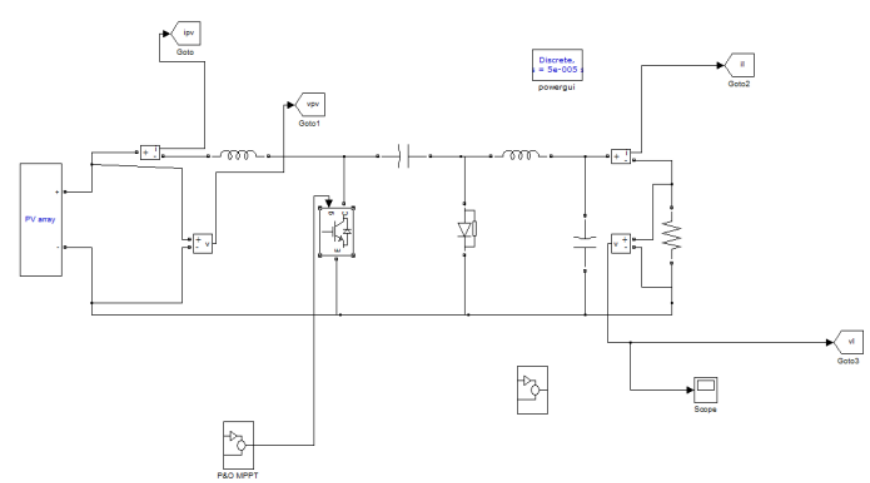

Fig. 3 proposed model of Stand-Alone PV Power Generation with Energy Storage Device

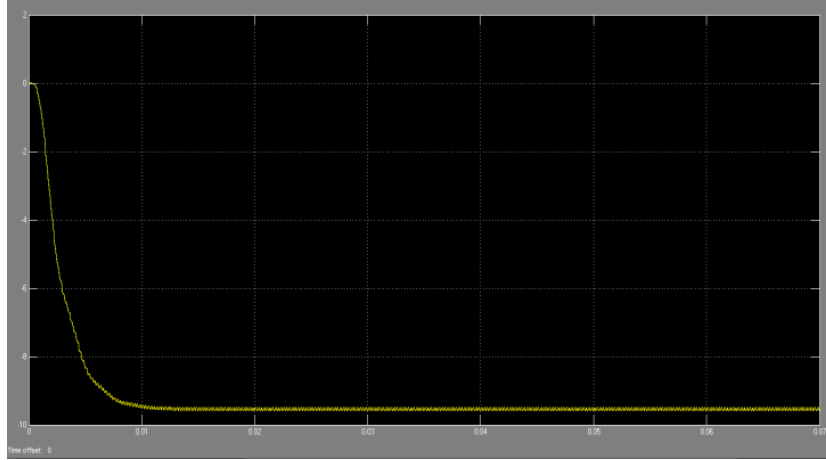

Fig.4 Simulation result of proposed model 
ISO 3297:2007 Certified

Vol. 4, Issue 6, June 2017

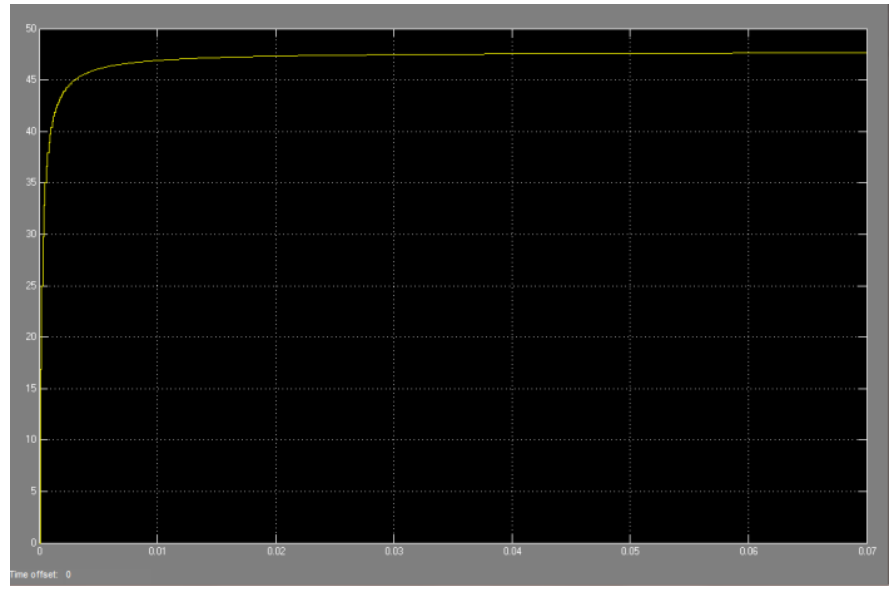

Fig.5 Simulation result of PV array model

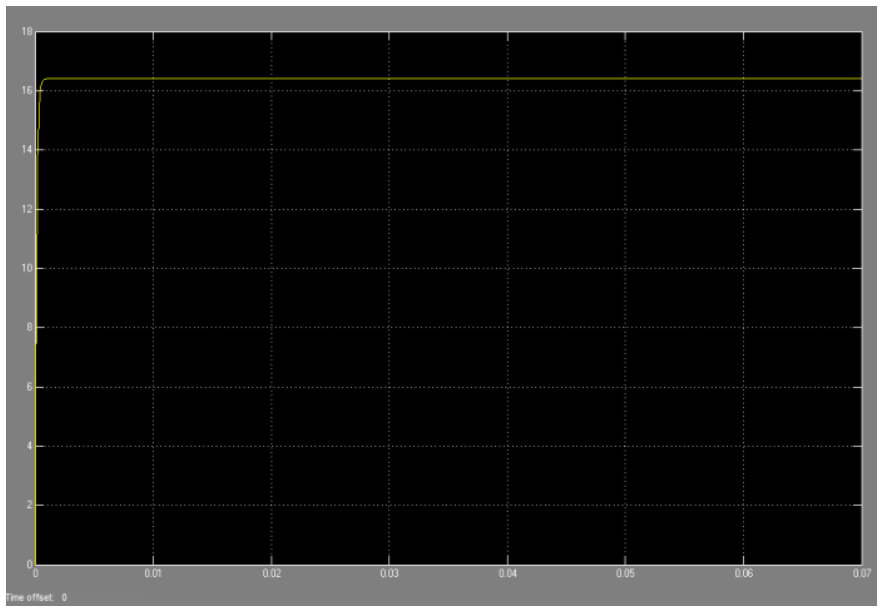

Fig.6 voltage graph respect to PV

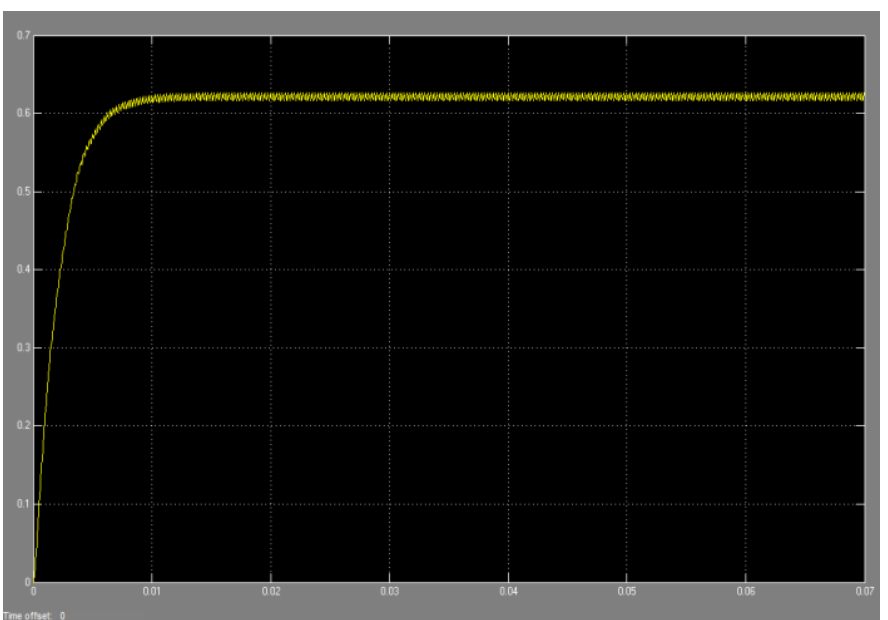

Fig.6.10 current graph respect to PV

\section{CONCLUSION}

The proposed control architecture of the PV-storage system, multiple operating modes such as PV-only, storage only, and PV-storage coupled are allowed without any instantaneous control configuration changes. the dynamic-response analysis and therefore the controller-design procedure of the versatile SPVS, as well as the lead-acid batteries because the energy storage devices, is studied. Each dc/dc converters are successfully controlled during a variable operation condition, and therefore the control strategy achieves fast and accurate control of the inverter output voltage, even with nonlinear loads and step-load changes. 


\section{IARJSET \\ Vol. 4, Issue 6, June 2017}

\section{REFERENCES}

[1] Thang, T. V., et al. "Flexible System Architecture of Stand-Alone PV Power Generation with Energy Storage Device" IEEE Transactions on Energy Conversion 30.4 (2015): 1386-1396.

[2] Nehrir, M. H., Caisheng Wang, Kai Strunz, Hirohisa Aki, Rama Ramakumar, James Bing, Zhixhin Miao, and Ziyad Salameh. "A review of hybrid renewable/alternative energy systems for electric power generation: Configurations, control, and applications" IEEE Transactions on Sustainable Energy 2, no. 4 (2011): 392-403.

[3] Zhou, Haihua, Tanmoy Bhattacharya, Duong Tran, Tuck Sing Terence Siew, and Ashwin M. Khambadkone. "Composite energy storage system involving battery and ultra capacitor with dynamic energy management in micro grid applications" IEEE transactions on power electronics 26 , no. 3 (2011): 923-930.

[4] Sechilariu, Manuela, Baochao Wang, and Fabrice Locment. "Building integrated photovoltaic system with energy storage and smart grid communication" IEEE Transactions on Industrial Electronics 60, no. 4 (2013): 1607-1618.

[5] Ziogou, Chrysovalantou, Dimitris Ipsakis, Costas Elmasides, and Spyros Voutetakis. "Automation infrastructure and operation control strategy in a stand-alone power system based on renewable energy sources" Journal of Power Sources 196, no. 22 (2011): 9488-9499.

[6] J.Jayapratha, A.Parimala "Stand-Alone PV Power Generation With Flexible System Architecture", IOSR Journal of Electrical and Electronics Engineering (IOSR-JEEE) 2016.

[7] Kim, Younghyun, et al. "A scalable and flexible hybrid energy storage system design and implementation" Journal of Power Sources 255 (2014): 410-422.

[8] Ahmed, Manzar, et al. "Integration of Renewable Energy Resources in Microgrid" Energy and Power Engineering 7.01 (2015): 12.

[9] B. Bose, "Global warming: Energy, environmental pollution, and the impact of power electronics" IEEE Ind. Electron. Mag., vol. 4, no. 1, pp. 6-17, Mar. 2010.

[10] F. Katiraei and J. R. Aguero, "Solar PV integration challenges" IEEE Power Energy Mag., vol. 9, no. 3, pp. 62-71, May/Jun. 2011

[11] D. A. Halamay, T. K. A. Brekken, A.Simmons, and S. McArthur, "Reserve requirement impacts of large-scale integration of wind, solar, and ocean wave power generation" IEEE Trans. Sustain. Energy, vol. 2, no. 3, pp. 321-328, Jul. 2011

[12] M. Fazeli, J. B. Ekanayake, P. Holland, and P. Igic, "Exploiting PV inverters to support local voltage-A small-signal model" IEEE Trans. Energy Convers., vol. 29, no. 2, pp. 453-462, Jun. 2014

[13] H. R. Teymour, D. Sutanto, K. M. Muttaqi, and P. Ciufo, "Solar PV and battery storage integration using a new configuration of a three-level NPC inverter with advanced control strategy" IEEE Trans. Energy Convers., vol. 29, no. 2, pp. 354-364, Jun. 2014.

[14] M. J. E. Alam, K. M. Muttaqi, and D. Sutanto, "A novel approach for ramp-rate control of solar PV using energy storage to mitigate output fluctuations caused by cloud passing" IEEE Trans. Energy Convers., vol. 29, no. 2, pp. 507-518, Jun. 2014.

[15] R. Shah, N. Mithulananthan, and K. Y. Lee " Large-scale PV plant with a robust controller considering power oscillation damping" IEEE Trans. Energy Convers., vol. 28, no. 1, pp. 106-116, Mar. 2013.

[16] C. Huang-Je, L. Yu-Kang, Y. Chun-Jen, and C. Shih-Jen, "Design and implementation of a photovoltaic high-intensity-discharge street lighting system" IEEE Trans. Power Electron., vol. 26, no. 12, pp. 3464-3471, Dec. 2011

[17] J. Margeta and Z. Glasnovic, "Introduction of PV energy into an existing HEP” IEEE Trans. Energy Convers., vol. 28, no. 1, pp. 717-727, Sep. 2011.

[18] C. Wang and M. H. Nehrir "Power management of a stand-alone wind/photovoltaic/fuel cell energy system" IEEE Trans. Energy Convers., vol. 23, no. 3, pp. 957-967, Sep. 2008. 